\title{
Parametric Study on Vibration Response for Automobile Crankshaft
}

\author{
Sanda Pyae Sone* \\ Intelligent Dynamics and System iKohza, MJIIT, Universiti Teknologi Malaysia \\ Malaysia \\ Aminudin Bin Abu \\ Intelligent Dynamics and System iKohza, MJIIT, Universiti Teknologi Malaysia \\ Malaysia \\ Oo Kyaw Nyein \\ Intelligent Dynamics and System iKohza, MJIIT, Universiti Teknologi Malaysia \\ Malaysia
}

*Corrosponding author’s Email: philip.sanda@gmail.com

\section{Research High I ights.}

In the interest of utilized more stable automobile components at high speed for reduction the vibration of mechanical system, dynamic characteristics analysis plays a vital role in complex mechanical parts. Factors influencing on the level of vibration response were determined and optimized by the approach of experimental design. Based on golbal and local proerties of crankshaft structural properties, it was found that main journal diameter and Young's modulus were recommended as inital values. Modification of crankshaft structure was performed carefully with the aspect of compatitablity for engine equipment. The reduction of vibration response was achieved and structure resonance has been shifted toward higher frequency domain. This approach proposed for the optimizing the structural parameters and would provide potential value basis to qualitative measure of parameters and determination of optimized structure.

\section{Graphical A bstract}




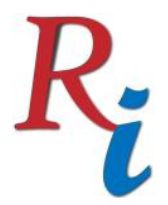

Asia Proceedings of Social Sciences

(APSS)

www.readersinsight.net/APSS
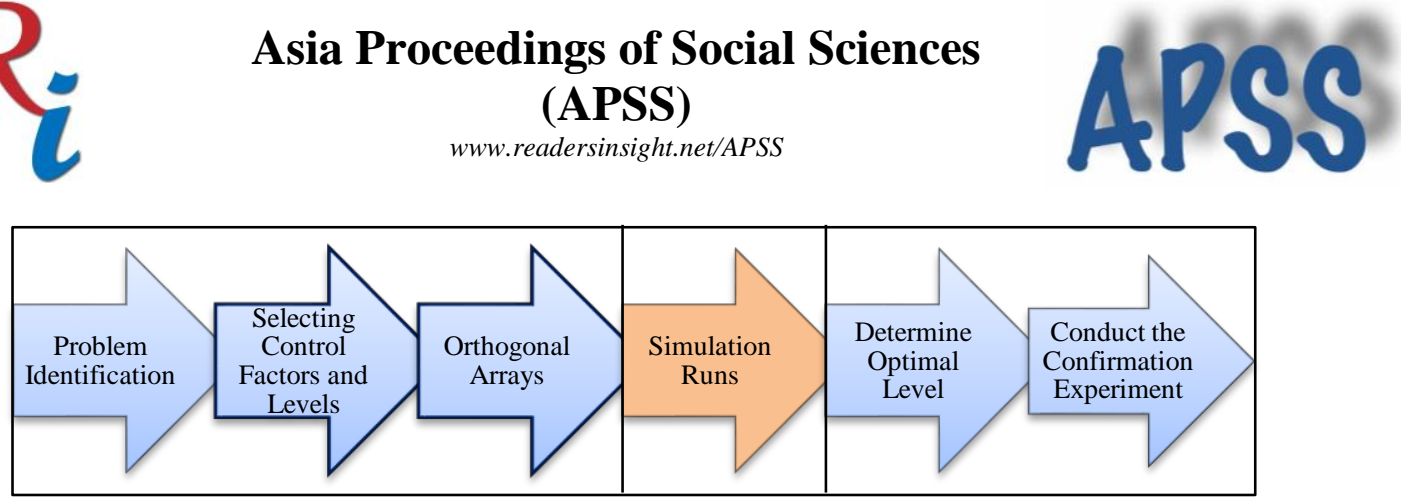

Pre Processing

Processing

Post Processing

\section{Research Objectives}

The task of seeking an optimum crankshaft for an automobile crankshaft which can reduce the vibration has made this study more challengeable. Zetty RMS et al. investigated the effect of sensitivity by modifying mass and stiffness on crankshaft structure to identify dynamic characteristics of crankshaft (Zetty et al., 2015 \& Kakade \& Pasarkar, 2015). The more complex the model, the more complex the design variables and parameters condition involved in mathematical model. A. Albers et al. optimized the crankshaft imbalance by utilizing multiobjective tools such as evolutionary design (ED) and genetic algorithms (GAs) (Albers et al., 2009). In order to solve the above problem, the engineering method of improvement can be solved by using design of experiment This method uses design parameters to minimize the vibration sensitivity to noise in a quality design manner. Aminuddin B.Abu et al. researched crankshaft vibration level by utilizing the combination of influencing factors (Abu et al., n.d.). In order to produces a good quality automobile that can compete marketplace, analyzing the characteristics of structure is crucial to obtain the best optimum design for vibration reduction and reliability, particularly of a crankshaft is a requirement of improving manufactures.

\section{Methodology}

Design of experiment is systematic and accurate approach to data collection to ensure the creation of robust engineering conclusions. Taguchi method finds the settings for the controllable variables which minimizes the variability from the uncontrollable noise factors (Montgomery, 2012) Several control factors like geometrical parameters can be considered mainly such as crankpin diameter, main journal diameter, width of web, web thickness, pulley diameter, flywheel flange diameter and width of counterweight and Young modulus for the material properties. Therefore, eight factors assigned in orthogonal array of experimental design. In the Taguchi method, the variables or parameters design is called the control factor and each factor can be determined by changing its value to $2 \sim 3$ steps which is called a level (Abu et al., n.d.) To consider the design for optimization of the crankshaft, the technique of optimization using design of experiment is applied. These eight factors are assigned to the first eight columns in the $\mathrm{L}_{18}$ array, resulting in the treatment combinations. $\mathrm{L}_{18}\left(2^{1} \times 3^{7}\right)$ orthogonal array has been used, it only requires 18 numbers of testing to be run numerically. Thus, if the control factors running by its sequence on each control factor, the influencing factor for the crankshaft can be examined. 


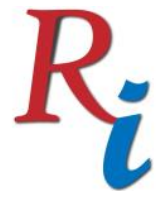

\section{Asia Proceedings of Social Sciences (APSS) \\ www.readersinsight.net/APSS}

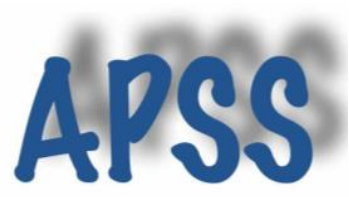

\section{Results}

Of the total 18 runs, all simulations have been completed successfully together with both modifications in material status and geometrical development. Since the analysis becomes tractable and the laboratory test follow the Gaussian distribution (Curtis et al., 1971).

Due to structural modifications, various vibration levels are generated with respect to each crankshaft model. After computing FRF data, vibration responses are calculated to observe the vibration level of each crankshaft experimental model. Based from these responses, optimum parameters can be determined by using Taguchi method.

The level of optimum parameter set points are the set point with the highest Signal to Noise ratio and provide the optimum response with the minimum effect due to noise. The data is generated from the simulated space defined by the factors and the range of their levels. The sensitivity for each control factor is higher due to larger changes of level of the $\mathrm{S} / \mathrm{N}$ ratio value. On the other hand, the larger changes of level $\mathrm{S} / \mathrm{N}$ ratio value means that reduction of vibration level is better for the reliability of the crankshaft. Regarding on the responses, main journal diameter obtained the highest $\mathrm{S} / \mathrm{N}$ ratio and is the most sensitive control factors for the optimization of the crankshaft.

\section{Findings}

Structural modifications are considered with geometrical parameters as well as material characteristics. The responses are obtained in terms of FRF graphs to evaluate influencing factors with optimum level. A proposed methodology improves the vibration response level based on frequency response of crankshaft structure. The larger changes of signal to noise $(\mathrm{S} / \mathrm{N})$ ratio value means that the lesser the vibration response, which is better for the durability of the crankshaft. In the study, it is found that the initial values of Young's Modulus and main journal diameter are still the best. A further work will focus on the combination of algorithms in neural network together with Taguchi method.

\section{Acknowledgement}

All the tests were performed at Malaysia-Japan International Institute of Technology, Mechanical Precision Engineering Department, in the Intelligent Dynamics \& System iKohza. This work was mainly supported by the Intelligent Dynamics \& System iKohza, MalaysiaJapan International Institute of Technology (MJIIT), Universiti Teknologi Malaysia, Kuala Lumpur.

\section{References}




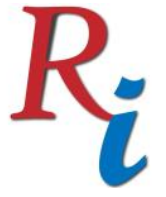

\section{Asia Proceedings of Social Sciences}

(APSS)

www.readersinsight.net/APSS

Abu, A., Aung, L.M., Sahekhaini, A., Zetty, R.M.S., Pyae Sone, S., n.d. On the Improvement of Vibration Level of Crankshaft System Using Design of Experiment.

Albers, A., Leon-Rovira, N., Aguayo, H., Maier, T., 2009. Development of an engine crankshaft in a framework of computer-aided innovation. Comput. Ind. 60, 604-612. https://doi.org/10.1016/j.compind.2009.05.017

Curtis, Allen, J., Tinling, N.G., Abstein, H.T., 1971. Selection and Performance of Vibration Tests, Vol. 8. ed. The Shock and Vibration Information Center.

Montgomery, D.C., 2012. Design and Analysis of Experiments, Eighth. ed. John Wiley \& Sons, Inc.

Zetty, R.M.S., Aminudin, B.A., Aung, L.M., Khalid, M.K., Norfazrina, H.M.Y., Raihan, N.M.R., 2015. Investigation of Sensitivity Effect Based on Mass and Stiffness Modification in Automobile Crankshaft. Appl. Mech. Mater. 752-753, 839-844. https://doi.org/10.4028/www.scientific.net/AMM.752-753.839

Peer-review under responsibility of $4^{\text {th }}$ Asia International Conference 2018 editorial board (http://www.utm.my/asia/our-team/) (C) 2018 Published by Readers Insight Publisher, lat 306 Savoy Residencia, Block 3 F11/1,44000 Islamabad. Pakistan, info@readersinsight.net This is an open access article under the CC BY-NC-ND license (http://creativecommons.org/licenses/by-nc-nd/4.0/). 